\title{
Impairment in dating and retrieving remote events in patients with early Parkinson's disease
}

\author{
Annalena Venneri, Paolo Nichelli, Giacomo Modonesi, Maria Angela Molinari, \\ Riccardo Russo, Carla Sardini
}

\begin{abstract}
Remote memory has been studied in a group of 25 non-demented patients with Parkinson's disease and their performance has been compared with that of 22 healthy control subjects. Only patients who scored $\geqslant 27$ on the mini mental state examination and with no anticholinergic treatment were included in the sample. A remote memory questionnaire was given, to evaluate memory for public events that occurred from 1966 to 1990. Each event was probed with five questions concerning its content and one for the date. Compared with healthy subjects, patients with Parkinson's disease were significantly impaired both in recalling the content and in dating remote events. These results support the claim that remote memory in patients with Parkinson's disease is disrupted independently of dementia. This impairment might result from a dysfunction at the level of the circuit connecting the basal ganglia to the frontal lobes.
\end{abstract}

(F Neurol Neurosurg Psychiatry 1997;62:410-413)

Department of Psychology, University of Aberdeen, UK A Venneri

Sezione di Neurologia, Dipartimento di Patologia

Neuropsicosensoriale,

Università di Modena,

Italy

A Venneri

P Nichelli

$G$ Modonesi

M A Molinari

C Sardini

Department of

Psychology, University

of Essex, UK

$R$ Russo

Correspondence to: Professor Paolo Nichelli, Sezione di Neurologia, Dipartimento di Patologia Neuropsicosensoriale, Università degli Studi di Modena, Via del Pozzo, 71 , 41100 MODENA, Italy.

41100 MODENA, Italy. and in revised form

15 October 1996

Accepted 10 December 1996 target event, and only when they failed to recall it, did we offer a multiple choice recognition procedure. A graded score was thus obtained depending on the number of cues needed to recall each event. Because we were interested in the effect of a putative prefrontal dysfunction in causing remote memory impairment in patients with Parkinson's disease we only examined patients with early Parkinson's disease, without any detectable sign of dementia.

\section{Methods}

SUBJECTS

The subject group comprised 25 patients with Parkinson's disease (mean age $60 \cdot 4$ (SD 7.3); mean education 5.8 (SD 1.9) years), and 22 age matched healthy control subjects (mean age 62.3 (SD 4.7); mean education 6.9 (SD $2 \cdot 7$ ) years). The mean duration of disease was 3.05 (SD 3.0) years. The mean mini mental state score for the patients with Parkinson's disease was 28.7 (SD 1.1), and 29.4 (SD 0.9) for the control subjects.

Subjects were recruited through the outpatient clinic of the neurological department of the University of Modena (Italy). Only ambulatory patients with early idiopathic Parkinson's disease were included. One patient was in stage 1 of the Hoehn and Yahr scale. ${ }^{3}$ The remaining 24 patients were in stage 2. The diagnosis of idiopathic Parkinson's disease was made by a neurologist based on the asymmetric onset of bradykinesia associated with either rigidity or resting tremor. Only patients with pronounced responsiveness to levodopa were included in the study. Exclusion criteria were history of neurological illness other than Parkinson's disease, psychiatric illness, head trauma with loss of consciousness, medical illnesses, or medications adversely affecting cognition, and substance misuse. Patients either taking anticholinergic medications or scoring $<27$ on the mini mental state examination ${ }^{4}$ were also excluded from the study. All patients were receiving antiparkinsonian medication at the time of the study. These comprised carbidopa-levodopa, benserazide-levodopa, amantadine $\mathrm{HCl}, \mathrm{L}-$ deprenyl, and bromocriptine. Normal controls were spouses or relatives of patients participating in the study. 
Patients with Parkinson's disease did not differ from normal controls with respect to age $\left(t_{45}=0.99, \mathrm{NS}\right)$ or years of formal education $\left(t_{45}=1 \cdot 56, \mathrm{NS}\right)$.

\section{MATERIALS AND PROCEDURE \\ Stroop test}

This test measures cognitive flexibility. We used a 30 item shortened version ${ }^{5}$ of the original test. It comprises three parts: naming the colour of dots, reading black and white colour names, and naming the colour in which colour names are printed. Performance was evaluated in terms of errors and execution time.

\section{Wisconsin card sorting test}

The purpose of this test is to assess the ability to form abstract concepts, and to maintain and shift the set. We used the modified procedure of Nelson et $a l^{6}$ which requires subjects to sort 48 cards one by one according to a category that must be deduced from the examiner's feedback. After six consecutive correct responses, the subject is informed that the sorting category has changed. Performance was evaluated in terms of percentage of perseverative errors and number of sorting categories that had been identified.

\section{Public event questionnaire}

The test explored the subjects' knowledge about 25 events which occurred between 1966 and 1990. This period was chosen to match adulthood of the patients and normal subjects. We selected one event for each year. Only events that were likely to be familiar to most of the Italian population were chosen. For each event we prepared a question asking for information related to the event. If the subject could not respond correctly, information about the target event was provided with a progressive cueing method. For example, a question was the following: "A bomb destroyed the waiting room of a train station in an Italian town. What is the name of the town?" If the subjects could not remember the correct answer (Bologna), we added the following cue: "Several 10 s of people died and many were wounded as a consequence of the explosion". If there was no correct response, two further cues were added, one at a time: "The event occurred at 1025 am" (a photograph of the event depicting the station clock at the precise time of the explosion had been printed by the main Italian newspapers and shown on television) and "A neofascist group was charged with having placed the bomb". If none of these cues triggered the production of the correct answer, subjects were offered four choices among which they had to select the correct response. In the example these were: "Milan, Brescia, Florence, Bologna". Finally, in the case of wrong recognition, subjects were asked if they had any recollection of the event at all. Whenever subjects either provided the correct response or could recollect the event but were unable to come up with the correct answer, they were asked to recall the year in which the event had occurred.

Both content information and dating per- formance were separately scored for each question.

\section{Content information score}

Content information score depended on the number of cues needed to produce the right answer. Subjects recalling the target event without any cue obtained a score of five. Four, three, and two points were assigned to subjects requiring respectively one, two, or three cues. When subjects could only recognise the correct answer among the alternatives, they scored one point. Scores on questions concerning five consecutive years were summed together. Five scores were hence obtained, one for each of the periods: $1966-70 ; 1971-5 ; 1976-80 ; 1981-5$; 1986-90.

\section{Dating}

Dating performance was evaluated taking into account three different variables:

Dating error-The absolute values of the difference between the estimated and the real date of the event were clustered and averaged across five consecutive years resulting in five five year period values for each subject.

Dating bias-The slope of the linear regression of estimated versus real dates of the events was computed to measure the so called "forward telescoping effect"-that is, the effect by which subjects tend to report a date more recent than the real one.

Dating precision-From the linear regression of estimated versus real dates we computed a score defined by the following formula:

1 -(residual variance/total variance)

This score was used to indicate the closeness with which dates provided agreed with one another (they were consistent with any specific bias).

\section{STATISTICS}

The distribution of data points did not always conform to a normal distribution and variances were not homogeneous between data sets. Therefore, unless stated otherwise, $\mathrm{P}$ values reported were obtained by means of the non-parametric Mann-Whitney two tailed $U$ test. Results are presented as means (SEM)

\section{Results}

Patients with Parkinson's disease showed no interference effects on the Stroop test. Their performance did not differ either in terms of errors (patients 3.2 (0.53); normal controls $1.5(0.4)$, NS) or in terms of execution time (patients 25.9 (3.42); normal controls 21.2 $(2 \cdot 57), \mathrm{NS})$.

On the Wisconsin card sorting test, patients with Parkinson's disease identified fewer categories $(2 \cdot 80(0 \cdot 252))$ than controls $(4.05$ $(0.341), P=0.009)$ and made a larger number of perseverative errors $(4.92(0.750))$ than controls $(2 \cdot 14(0.595), P=0.006)$.

Scores on the public event questionnaire distributed normally and data were assessed by analysis of variance (ANOVA). Patients with Parkinson's disease recalled fewer events without any cueing than controls $(8.56$ 
Figure 1 Mean content information scores in each five year period. $P D=$ Parkinson's disease.

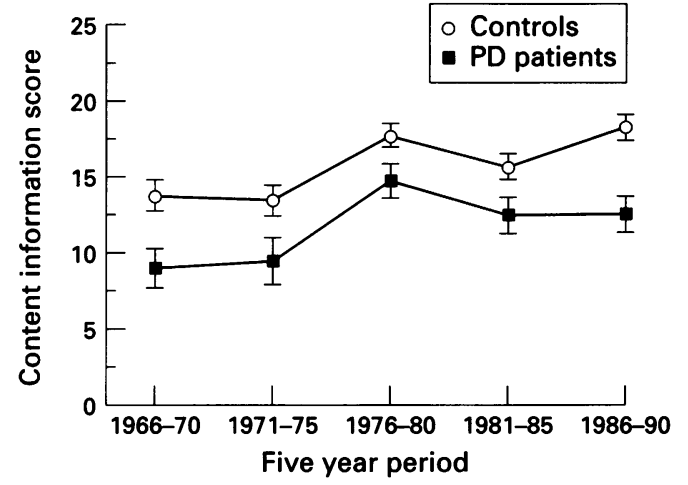

(1.066) $v 12.86(0.910), P=0.004)$. When groups were compared for number of items recalled in free recall, cued recall (one, two, or three cues), and recognition, there was a very highly significant effect $(F=115.028$, df 4 , $\mathrm{P}<0.0001$ ) of recall condition, but there was also a very highly significant interaction between recall condition and group $(F=$ $5 \cdot 467$, df $4, P=0.0004)$. Post hoc comparisons showed that there was no difference between the two groups for cued response and recognition, but they differed in performance in free recall. Figure 1 shows the average content information scores obtained by control subjects and patients with Parkinson's disease on the five five-year periods of the public event questionnaire. Results of ANOVA on these scores showed that events concerning more recent time periods were better recalled than earlier ones $(F=26.932$; df 4,180 ; $P<0.0001)$. patients with Parkinson's disease were worse than control subjects at recalling the event content $(F=9 \cdot 297$; df 1,45 ; $\mathrm{P}<0.0038)$ but there was no interaction between group and content score $(F=1.548$, df 4,180 , NS) - that is, the temporal gradient was similar in the two experimental groups.

Figure 2 shows dating errors averaged across five year periods in normal controls and in patients with Parkinson's disease. The results of the two groups were compared by ANOVA. As expected, dating errors were greater for earlier than for more recent events $(F=60.671 ;$ df $4,180, \mathrm{P}<0.0001)$. Patients with Parkinson's disease were significantly less accurate than normal controls in dating $(F=$ 6.612 ; df $1,45 \mathrm{p}=0.01$ ). However, there was no interaction between group and dating error ( $F=0 \cdot 281$, df 4,180 , NS).

Only two subjects (one control and one

Figure 2 Mean dating errors in each five year period. $P D=$ Parkinson's disease. patient with Parkinson's disease) obtained a dating bias value greater than unity $(1 \cdot 1$ and $1 \cdot 0$, respectively). All the remaining subjects showed a "forward telescoping effect" (they tended to record events as more recent than they actually were). Dating bias was 0.68 $(0.045)$ in normal subjects and $0.56(0.054)$ in patients with Parkinson's disease. There was no significant difference between the two groups $(P=0 \cdot 20)$.

Dating precision was greater in controls $(0.63(0.033))$ than in patients with Parkinson's disease $(0.48(0.042) ; \mathrm{P}=0.01)$.

The total content information score was related both to the number of categories $(r=$ $0.40 ; P=0.006$ ) and to the number of perseverative errors $(r=0.45 ; \mathrm{P}=0.001)$ on the Wisconsin card sorting test, which is commonly considered to be a task sensitive to frontal lobe impairment. ${ }^{67}$

\section{Discussion}

Different from previous findings, ${ }^{12}$ our results showed that non-demented patients with Parkinson's disease are impaired both in retrieving the content and in dating old memories. In the experiments of Freedman et $a l^{1}$ and Sagar et $a l^{2}$, recall of public events was tested by means of pictures, either of famous faces $^{1}$ or of famous scenes. ${ }^{2}$ This supposedly might have provided powerful visual cues that led to the underscore of a defective recall of content information. The procedure we adopted, providing graded scores for spontaneous and cued recall, might have permitted us to detect subtler impairments in remote memory.

Several studies ${ }^{8-11}$ have provided evidence that prefrontal structures play a key part in planning a systematic search for old memories. The frontal lobes are directly connected to the basal ganglia through a complex circuit including the caudate nucleus, thalamus, substantia nigra, and globus pallidum. It has been suggested $^{12}{ }^{13}$ that reduction in dopamine in this complex circuit-especially in the caudate nucleus-added to dopamine depletion in the corticomesial limbic system, causes decreasing dopamine concentrations in the frontal cortex, which clinically results in deficit in the so called "frontal tasks". Indeed, as shown in other studies, ${ }^{14-19}$ we found non-demented patients with Parkinson's disease to be defective on the Wisconsin card sorting test, which is commonly held to be sensitive to frontal lobe dysfunction.

Previous work ${ }^{1520}$ has shown that patients with Parkinson's disease are impaired on recall but not recognition memory tests, suggesting that the effort demanding retrieval processes necessary for recall may result in impaired performance. Accordingly, the remote memory impairment we found in patients with Parkinson's disease may be the result of their difficulty in planning the retrieval of old memories. As a consequence, patients with Parkinson's disease were able to recall fewer events spontaneously and needed a larger number of cueing aids for reaching the correct answer compared with normal subjects. 
Baddeley and Wilson ${ }^{21}$ argued that patients with frontal lesions are incapable of activating the problem solving component of memory retrieval. Following an alternative explanation, ${ }^{22}$ the prefrontal cortex stores complex knowledge units (managerial knowledge units (MKUs)), which unite a series of events that occur or occurred in our life. Remote memory deficits might follow prefrontal damage because of a loss of these representations.

We argue that Parkinson's disease may cause a similar impairment because of failure in accessing MKUs, which might parallel their impairment in accessing motor representations.

We thank Augusto Scaglioni who referred some of the patients with Parkinson's disease. PN was funded by the Italian National Research Council; AV was supported by the European Science Foundation.

1 Freedman M, Rivoira P, Butters N, Sax DS, Feldman RG. Retrograde amnesia in Parkinson's disease. Can $\mathcal{f}$ Neurol Sci 1984;11:297-301.

2 Sagar HJ, Cohen NJ, Sullivan EV, Corkin S, Growdon JH. Remote memory function in Alzheimer's disease and Remote memory function in Alzheimer's dise

3 Hohen MM, Yahr MD. Parkinsonism: onset, progression, and mortality. Neurology 1967;17:427-42.

4 Folstein MF, Folstein SE, McHugh PR. "Mini-mental state": a practical method for grading the cognitive state of patients for the clinician. F Psychiatr Res 1975;12: 189-98.

5 Venneri A, Molinari MA, Pentore R, Cotticelli B, Nichelli P, Caffarra P. Shortened Stroop color-word test: its application in Alzheimer's disease. In: Nicolini M, Zatta PF, Corain B, eds. Alzheimer's disease and related disorders. London: Pergamon Press, 1993:81-2.

6 Nelson HE A modified card sorting test sensitive to frontal lobe defects. Cortex 1976;12:313-24.

7 Milner B. Effects of different brain lesions on card sorting test: the role of frontal lobes. Arch Neurol 1963;9:100-10.
8 Cohen NJ, Squire LR. Retrograde amnesia and remote memory impairment. Neuropsychologia 1981;19:337-56.

9 Kopelman MD. Autobiographical memory in clinical research and practice. In: Conway MA, Ruben DC, Spinnler $\mathrm{H}$, Wagenaar $\mathrm{W}$, eds. Theoretical perspectives on autobiographical memory. The Netherlands: Kluwer Publications, 1992:427-50.

10 Squire LR, Cohen NJ. Remote memory, retrograde amnesia and the neuropsychology of memory. In: Cermak LS, ed. Human memory and amnesia. Hillsdale, NJ: Erlbaum, 1982:275-303.

11 Kopelman $\mathrm{MD}$. The neuropsychology of remote memory. In: Spinnler H, Boller F, eds. The handbook of neuropsychology. Vol 8. Amsterdam: Elsevier, 1993:215-38.

12 Scatton B, Javoy-Agid F, Rouquier L, Dubois B, Agid Y. Reduction of cortical dopamine, noradrenaline, serotonin and their metabolites in Parkinson's disease. Brain Res and their metabolit

13 Hornykiewicz O, Kish SJ. Neurochemical basis of dementia in Parkinson's Disease. Can $\mathcal{F}$ Neurol Sci 1984;11: 185-90.

14 Lees AJ, Smith E. Cognitive deficits in the early stages of Parkinson's disease. Brain 1983;106:257-70.

15 Taylor AE, Saint-Cyr JA, Lang AE. Frontal lobe dysfunction in Parkinson's disease: the cortical focus of neostriatal outflow. Brain 1986;109:845-83.

16 Taylor AE, Saint-Cyr JA, Lang AE. Parkinson's disease: cognitive changes in relation to treatment response. Brain 1987;110:35-51.

17 Taylor AE, Saint-Cyr JE. Executive functions. In: Huber SJ, Cummings JL, eds. Parkinson disease: neurobehavioral aspects. New York: Oxford University Press, 1990.

18 Gotham AM, Brown RG, Marsden CD. "Frontal" cognitive function in patients with Parkinson's disease "on" and "off" levodopa. Brain 1988;111:299-321.

19 Canavan AGM, Passingham RE, Marsden CD, Quinn N, Wyke $M$, Polkey CE. The performance on learning tasks of patients in early stages of Parkinson's disease. Neuropsychologia 1989;27:141-56.

20 Brown RG, Marsden CD Cognitive function in Parkinson's disease: from description to theory. Trends Neurosci 1990 13:21-29.

21 Baddeley A, Wilson B. Amnesia, autobiographical memory, and confabulation. In: Rubin DC, ed. Autobiographical memory. Cambridge: Cambridge University Press, 1986: 225-52.

22 Grafman J. Alternative frameworks for the conceptualization of prefrontal lobe functions. In: Boller $\mathrm{F}$, Grafman eds. The handbook of neuropsycholog. Vol 9 . Amsterdan J Elsevier, 1994:187-201. 